\title{
Observation of the long-period monotonic seismic waves of the November 11, 2018, Mayotte event by Iranian broadband seismic stations
}

\author{
Hossein Sadeghi ${ }^{* *}$ (1) and Sadaomi Suzuki ${ }^{2}$
}

\begin{abstract}
On November 11, 2018, an event generating long-lasting, monotonic long-period surface waves was observed by seismographs around the world. This event occurred at around 09:28 UTC east of the Mayotte Island, in the Indian Ocean off the coast of East Africa. This event is unusual due to the absence of body waves in the seismograms and no feeling of earth shaking by people locally. The purpose of this study is to investigate this unusual event using the waveforms recorded by 26 stations of the Iranian National Broadband Seismic Network. The stations are located at epicentral distances ranging from 4542 to $5772 \mathrm{~km}$ north-northeast of the event's epicenter. The arrival of monochromatic long-period signals is visible around 10 UTC in the recordings of all the stations and the signals lasted for more than $30 \mathrm{~min}$. Frequency analysis of the seismograms shows a clear peak at $0.064 \mathrm{~Hz}$ ( $15.6 \mathrm{~s} / \mathrm{cycle}$ ). The maximum amplitude of the transverse components is less than a half of the radial components. This is in agreement with the theoretical radiation pattern of Rayleigh and Love waves at a frequency of $0.06 \mathrm{~Hz}$ for a vertical compensated linear vector dipole source mechanism. The average apparent phase velocities were calculated as 3.31 and $2.97 \mathrm{~km} / \mathrm{s}$, in the transverse and radial directions, corresponding, respectively, to Love and Rayleigh waves in the frequency range of $0.05-0.07 \mathrm{~Hz}$. A surface wave magnitude of Ms $5.07 \pm 0.22$ was estimated. Just before the monochromatic signal arrives, there is some dispersion in the surface waves. This observation may suggest a regular earthquake of Ms $4.3 \pm 0.11$ that triggered the November 11, 2018, event. The difference between the arrival times of the recorded surface waves of the two events is estimated to be less than $31 \mathrm{~s}$, and most likely of $\sim 7 \mathrm{~s}$ only.
\end{abstract}

Keywords: Mayotte Island, Monochromatic very-long-period signal, Trigger earthquake, Iranian broadband stations

\section{Introduction}

The November 11, 2018, Mayotte event was first introduced in the media by Wei-Haas (2018) in National Geographic as a strange earthquake in which seismic waves were recorded by instruments around the world, but, unusually, nobody felt shaking. The event occurred offshore around 9:28 UTC near Mayotte Island in the

\footnotetext{
*Correspondence: sadeghi@um.ac.ir

${ }^{1}$ Department of Geology, Faculty of Science, Ferdowsi University of Mashhad, Mashhad, Iran

Full list of author information is available at the end of the article
}

Mozambique Channel between the northern tip of Madagascar and the eastern coast of Africa. Mayotte Island is one of the four main islands in the volcanic Comoros archipelago. The November 11 Mayotte event, in the absence of body waves, caused large, long-lasting, monotonic long-period surface waves that traveled around the globe. Before May 2018, the seismic activity in this archipelago was dispersed and moderate, with only a few earthquakes having a magnitude greater than 4 . But in the year following the Mayotte volcanoseismic sequence on May 10, 2018, 32 earthquakes with a magnitude greater than 5 were recorded (Lemoine 
et al. 2020). The biggest earthquake ever recorded in the area was a Mw 5.9 event that happened on May 15, 2018 (USGS). Figure 1 shows the recorded waveforms for the May 15, 2018, earthquake, and the Mayotte event at a regional station, ABPO, Ambohimpanompo, Madagascar (part of the global IRIS/IDA seismic network), and at a teleseismically distant station, ASAO, Ashtian, Iran (part of the Iranian National Broadband Seismic Network). The epicenters of these two events were located very close to each other, and the epicentral distances were 713 and $5261 \mathrm{~km}$ from the ABPO and ASAO stations, respectively. The waveforms show clear differences in the nature of the propagated waves between the regular earthquake and the Mayotte event. The most obvious feature of the Mayotte event is that while large long-period monotonic surface waves are visible, body waves are absent. The long-period waves appeared for more than $30 \mathrm{~min}$ at both the regional and teleseismic distances. Moreover, several smaller tremors with similar characteristics were recorded during the 2018-2019 Mayotte seismo-volcanic crisis (Cesca et al. 2020). Thus, there is still much to learn about these very-long-period (VLP) signals occurring during the Mayotte event. We call the November 11 event the "monotonic very-long-period" signal and abbreviate it as MVLP. The event has been described in the framework of underwater volcanic activity, as the result of the resonance of a deep magma reservoir, in response to the sagging of the reservoir roof (Cesca et al. 2020). In this study, we investigate this event using the waveforms recorded by the Iranian National Broadband Seismic Network. The objective of our study is to characterize the seismic signal and its source by analyzing seismic data recorded by the Iranian National Broadband Seismic Network: in particular, we aim at (1) evaluating its spectral properties, (2) estimating the magnitude, and (3) assessing the occurrence of an earthquake just before the event for possible interaction that may have triggered the event.

This work extends previous results (Cesca et al. 2020; Lemoine et al. 2020), which partially addressed these objectives, by investigating the largest VLP signal in the light of teleseismic recordings at a dense regional seismic network.

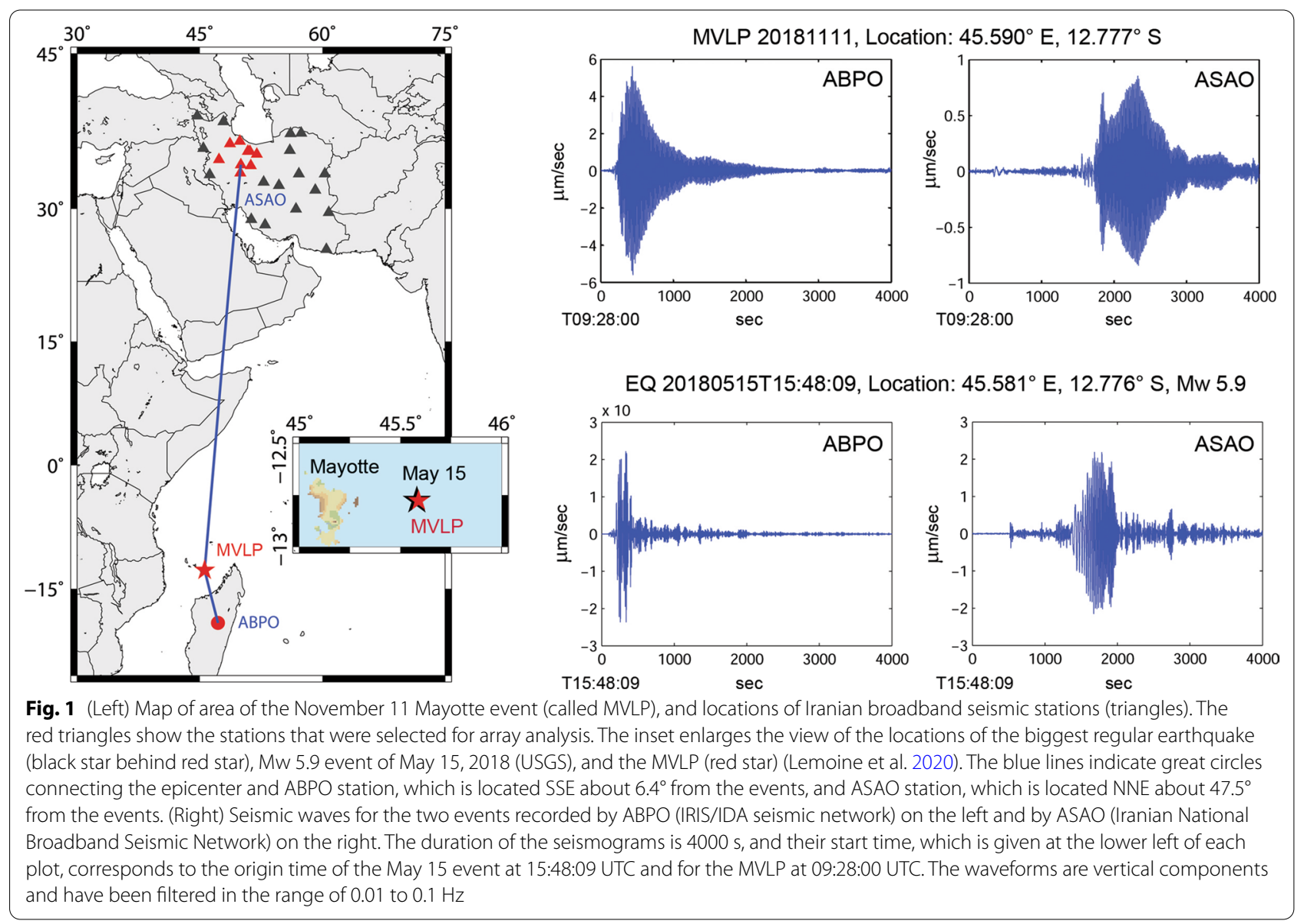


(See figure on next page.)

Fig. 2 One-and-a-half hour trace view of the vertical components of MVLP observed by Iran's 26 broadband stations. Columns (a) and (c) show the normalized waveforms, and columns (b) and (d) show the corresponding normalized Fourier amplitude spectra. The traces are ordered from top to bottom by increasing epicentral distance (station name and epicentral distance are displayed). The waveforms are bandpass filtered between 0.01 and $0.1 \mathrm{~Hz}$. Long-lasting, long-period seismic waves are observed to arrive at around 10:00 UTC on November 11, 2018. The Fourier spectra are for unfiltered seismograms. The peak of the spectra (indicated by the gray arrow in the two bottom spectra) is at $0.064 \mathrm{~Hz}$ (15.6 s/cycle)

\section{Observations}

The broadband seismic network of the Iran International Institute of Earthquake Engineering and Seismology (IIEES) started operating with 4 stations in 1998 and currently has 31 stations (IIEES 2020). The stations are equipped with Güralp CMG-3 T sensors with a flat velocity response from $120 \mathrm{~s}(0.0083 \mathrm{~Hz})$ to $50 \mathrm{~Hz}$. Twenty-six of the stations (triangles in Fig. 1) were in operation on November 11, 2018, and recorded the MVLP. The stations are located from 4542 to $5772 \mathrm{~km}$ north-northeast of the MVLP's epicenter, which was assumed from the study of Lemoine et al. (2020). A 1.5-h trace view of the vertical component of the broadband records filtered between 0.01 and $0.1 \mathrm{~Hz}$, and the frequency spectra of their unfiltered waveforms, are displayed in Fig. 2. All the stations show clear long-period seismic waves arriving around 10:00 UTC on November 11, 2018, and a frequency analysis of the seismograms shows a clear peak in the spectral amplitudes. The peak is in a narrow frequency band of $0.05-0.07 \mathrm{~Hz}$. Among the stations, no significant changes are observed in the monochromatic wave trains and the narrow-band spectral peak.

\section{Seismic waves and focal mechanisms}

We compared the seismic waves for the MVLP and the largest regular earthquake (called "May 15" in Fig. 1 and hereafter). Figure 3 shows the seismic waves for the three components observed at the ASAO station. The ground noise level for the ASAO station is low. It is clear that the observed waveforms for the two earthquakes differ greatly even though the epicenters are close. The MVLP waveforms are dominated by long-lasting monochromatic surface waves, and body waves are lacking altogether. The maximum amplitude of the transverse component is less than a half of the radial component. Clear P- and S-phase arrivals are observed on the May 15 seismograms, and dispersion of the surface waves clearly appears in all three components on the seismograms. The maximum amplitude of the transverse component is 1.2 times that of the radial component. Figure 4a displays the focal mechanisms for the MVLP and May 15 events as beach-ball representations of their moment tensors (MTs). The MT components of the MVLP are proposed by averaging the MTs of 21 events with monochromatic long-duration and VLP signals that are provided in the seismic catalogs of the 2018-2019 crises that occurred east of Mayotte Island (Cesca et al.
2019). To eliminate the seismic moment (event size) effect, the components of each moment tensor were first normalized to 1 by dividing by the maximum absolute value of its elements, and then the normalized components were averaged (Eq. 1).

$$
\overline{\boldsymbol{M}}=\frac{1}{n} \sum_{i=1}^{n}\left(\frac{\boldsymbol{M}_{i}}{\left|\boldsymbol{M}_{i}\right|_{\max }}\right)
$$

where $\boldsymbol{M}_{i}$ is the MT of the $i$ th event and $\left|\boldsymbol{M}_{i}\right|_{\max }$ is the maximum absolute value of its elements, and $n$ is the number of MTs. The focal mechanism for May 15, from the (GCMT) catalog, indicates a dominant strike-slip with NW-SE-directed compression. Cesca et al. (2020) suggested a vertical compensated linear vector dipole (CLVD) for the Mayotte VLP events, which are not always exactly vertical. In a vertically symmetric CLVD, no Love waves or azimuthal variations in Rayleigh waves are expected, but the proposed focal mechanism for the MVLP shows no vertical symmetry axes. Previous studies discussed the relation between active volcanism and the occurrence of rarely observed non-double-couple earthquakes (e.g., Shuler et al. 2013a, b). Their study used a standard source time function as in a GCMT solution, while Cesca et al. (2020) modeled the VLP events with a damped resonator source time function. Although the present study cannot draw definitive conclusions, to compare the MVLP with a regular earthquake, we have to make a model for the radiation pattern of surface waves considering the MTs. Figure $4 \mathrm{~b}$ shows the theoretical seismic energy radiation patterns for Rayleigh and Love waves at a frequency of $0.06 \mathrm{~Hz}$. The spectral amplitudes based on the considered source mechanism were calculated with an azimuthal spacing of $1^{\circ}$ using the data product (Rösler and van der Lee 2020) of the IRIS DMC's Surface-Wave Radiation Pattern. Seismic radiation for the MVLP is dominated by Rayleigh waves displaying a nearly oval form with larger elongation in the northeastsouthwest direction. Love waves are clearly less energetic than Rayleigh waves and show more azimuthal variation in the maximum amplitude. Seismic radiation for May 15 shows larger spectral amplitudes for Love waves than for Rayleigh waves. The spatial variation of the maximum amplitude shows a clear four-lobe pattern for Love waves; while for Rayleigh waves, the radiation pattern has a twolobe shape. The broadband station in Iran is located in 

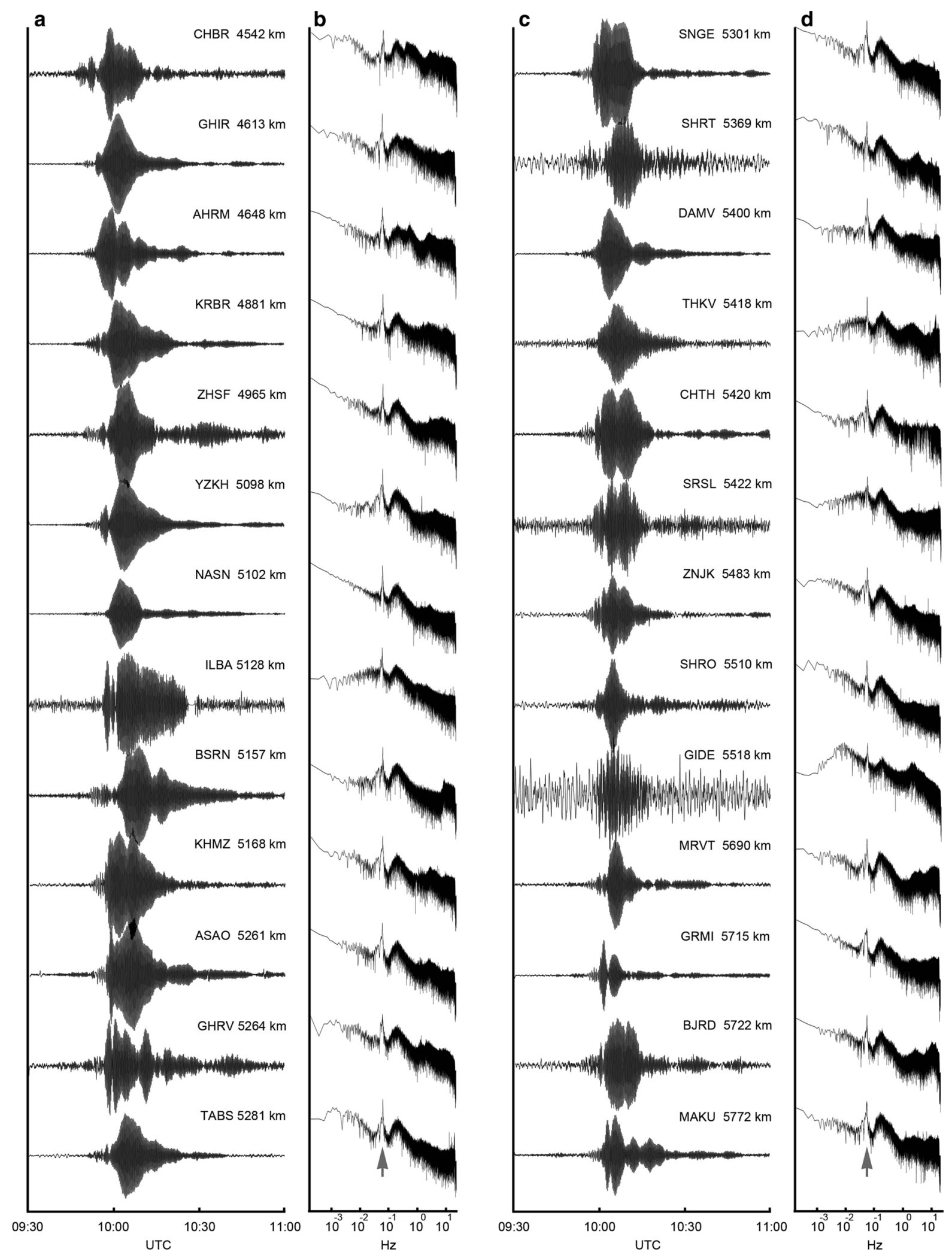

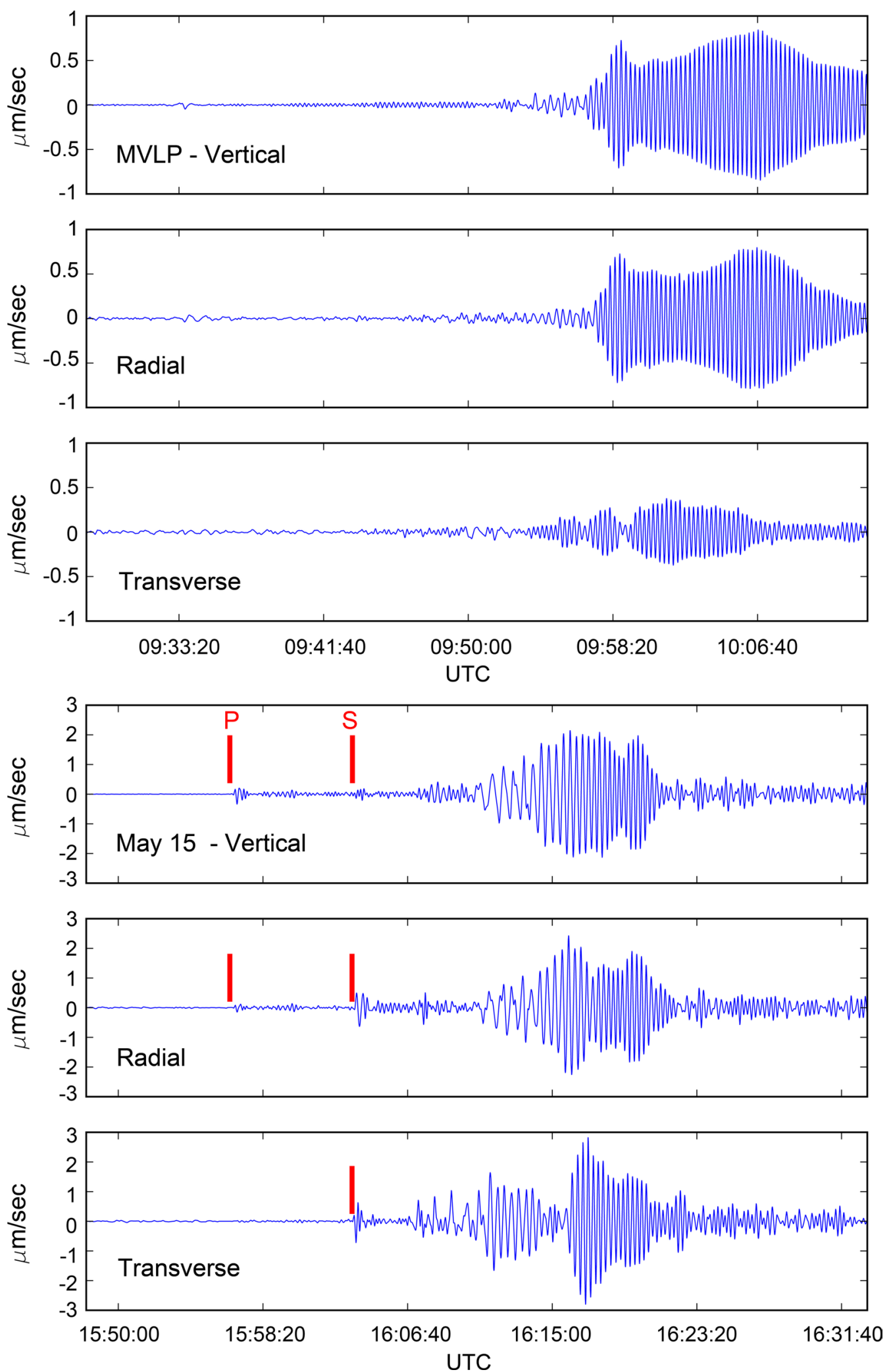

Fig. 3 Comparison of the vertical, radial, and transverse components for the MVLP (top) and May 15 (bottom) events observed at station ASAO. The waveforms show a length of $45 \mathrm{~min}$ and were filtered between 0.01 and $0.1 \mathrm{~Hz}$. Vertical short red lines in the waveforms in the bottom show the arrivals of $\mathrm{P}$ and $\mathrm{S}$ phases 


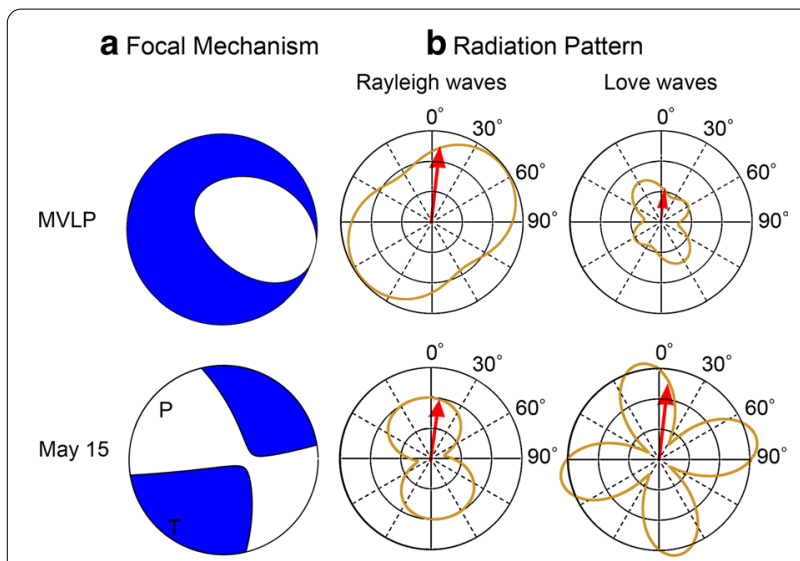

Fig. 4 a Focal mechanisms for the MVLP (top) and May 15 (bottom) events. The MVLP MT, which is defined by averaging the MTs of 21 VLPs proposed by Cesca et al. (2019), shows a vertical CLVD, while the focal mechanism for May 15 indicates dominant strike-slip faulting with a NW-SE-directed P-axis and NE-SW-directed T-axis. The relative components of the MVLP MT are defined as $M_{r r}=-1.0, M_{t t}=0.7$, $M_{p p}=-0.1, M_{r t}=-0.3, M_{r p}=0.8$, and $M_{t p}=-0.2$, and the May 15 MT is obtained from the GCMT catalogue. $\mathbf{b}$ Azimuthal radiation pattern for surface waves at a frequency of $0.06 \mathrm{~Hz}$ considering the moment tensors for the MVLP (top) and May 15 (bottom) events with source depths at 28 and $17 \mathrm{~km}$, respectively. The black circles show the relative spectral displacement amplitude on a linear scale for each pair of Rayleigh and Love waves. The red arrow points to station ASAO the azimuth range of $359^{\circ}-21^{\circ}$ from the MVLP and lies close to the maximum radiation point for the surface waves.

Figure 5 presents spectrograms of the power spectral density (PSD) in $(\mathrm{m} / \mathrm{s})^{2} / \mathrm{Hz}$, Fourier spectra, and dominant periods for the MVLP and May 15 vertical and transverse components at the ASAO station (the seismograms are shown in Fig. 3). As we expected from the model of the radiation pattern for the MVLP, the surface waves in the vertical components (dominated by Rayleigh waves) have larger amplitudes than the transverse components (Love waves). In addition, the MVLP shows four clear differences from regular earthquakes. The first obvious difference is the very long duration of its surface waves. The second difference can be seen through the spectrograms, where a dominant monochromatic surface wave (around $0.06 \mathrm{~Hz}$ ) extends throughout the signal duration. The Fourier spectra show a clear large peak at $0.064 \mathrm{~Hz}$. The third and fourth differences can be observed in the graph of the dominant period over time; the dominant period for the transverse component is lower than that for the vertical component, and the signals in both components propagate with nearly the same velocity. A convergence of surface wave velocities can also be seen in the graph of the dominant period for May 15 around a period of $16.5 \mathrm{~s}$ $(0.06 \mathrm{~Hz})$, which corresponds to the Airy phase with a

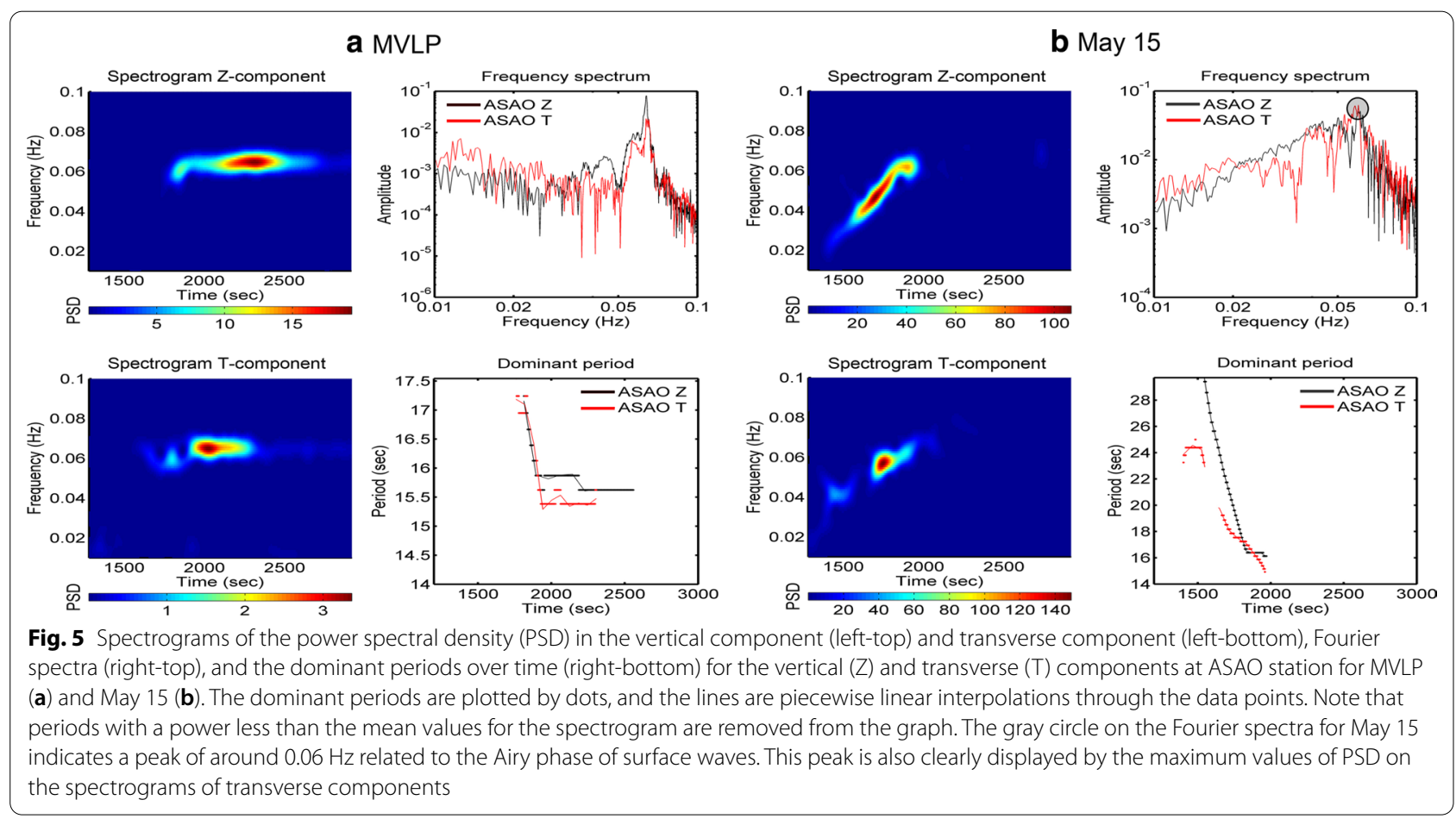




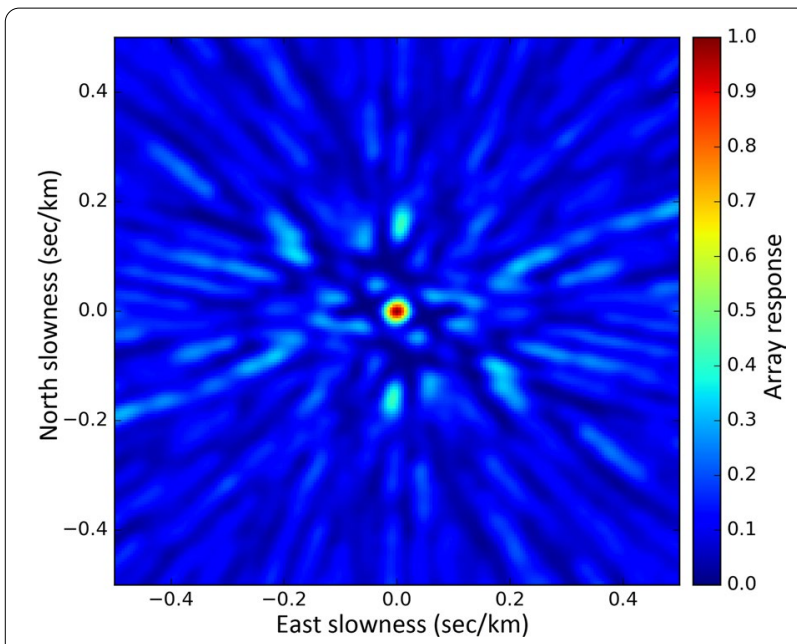

Fig. 6 Array response function at 0.05 to $0.07 \mathrm{~Hz}$. The color scheme corresponds to the normalized amplitude of the relative power, as shown by color bar on the right

minimum in the group velocity dispersion curves (Bullen and Bolt 1985). The Airy phases in the transverse component can be observed by large amplitudes after an abrupt termination in the wave trains (see Fig. 3, bottom). The gap between the red lines around $1600 \mathrm{~s}$ in the dominant period graph (right-bottom in Fig. 5b) for the transverse component are due to this termination, and also our criterion to select power values greater than the mean value of the PSD.

\section{Phase and group velocities of the surface waves}

We used two analysis methods, frequency-wavenumber (f-k) analysis and regression analysis, to estimate the group velocity of the MVLP surface waves. We applied $\mathrm{f}-\mathrm{k}$ analysis to a group of nine relatively closely spaced stations as an array using the python library Obspy (Beyreuther et al. 2010). The selected stations are marked by red triangles in the map in Fig. 1 . The array response function for the directional sensitivity and its resolution power are shown in Fig. 6. This function was computed for a frequency band of $0.05-0.07 \mathrm{~Hz}$. There are no distinct side lobes in the array response.

The semblance technique (Neidell and Taner 1971) was used to measure the slowness and back-azimuths of the coherent wave phases that crossed the array. The analysis was applied to 1-h sections from 2018-11-11, 09:45:00, to 2018-11-11, 10:45:00. After the waveform data were filtered using a bandpass filter with a bandwidth of 0.05$0.07 \mathrm{~Hz}$, the semblance coefficient was calculated for a sliding window length of $20 \mathrm{~s}$ in steps of $1 \mathrm{~s}$. The range of slowness was searched from 0.1 to $1.5 \mathrm{~s} / \mathrm{km}$ in steps of $0.05 \mathrm{~s} / \mathrm{km}$. The quality of the stacked signal was measured by the semblance coefficient, which is a dimensionless quantity between 0 and 1, representing no coherency and perfect coherency, respectively. The semblance values show a coherency peak at about $75 \%$ for the radial (Rayleigh waves) components (Fig. 7a). According to Lemoine et al. (2020), the latitude and longitude of the MVLP were $12.777^{\circ} \mathrm{S}$ and $45.590^{\circ} \mathrm{E}$, respectively, corresponding to a back-azimuth of $\sim 185^{\circ}$ from the center of the array. From Fig. $7 \mathrm{a}$, the back-azimuth was determined to be $\sim 200^{\circ}$, but its error was large. In contrast, for the transverse (Love waves) components, the semblance values did not show a unique peak and the coherency was higher than $55 \%$ (Fig. 7b). For the regression analysis, we manually picked the wave group arrivals for bandpass-filtered radial and transverse components for all 26 stations. One station was taken as a reference, and the relative delays, positive or negative, in arrival times for the other stations were calculated. Assuming a planar wavefront propagating horizontally with a constant apparent velocity across the array, the tau-p method (Havskov and Ottemöller 2010) was used. The apparent velocity and back-azimuth were estimated by fitting a plane wave, that is, a leastsquares regression line, to the time delays. The procedure was repeated using another station as a reference. The averages of the apparent velocities in the transverse and radial directions were calculated as 3.31 and $2.97 \mathrm{~km} / \mathrm{s}$, respectively. These correspond to the phase velocities of Love and Rayleigh waves, respectively, in the frequency band of $0.05-0.07 \mathrm{~Hz}$. Figure 8 shows the average backazimuth (black arrows). They are generally in good agreement with the back-azimuth to the MVLP epicenter (red arrows) according to Lemoine et al. (2020). In this figure, a clear pattern of back-azimuth errors from positive to negative moving from west to east in Iran is found. Such systematic errors can be due to velocity variations in the crust and upper mantle, while we assumed a homogenous structure.

\section{Estimation of magnitudes}

Using seismic data from the 26 Iranian seismic stations, we estimated the surface wave magnitudes $(M s)$ of the MVLP and the regular earthquakes occurring around Mayotte Island. We used Eq. (2), named the Prague formula (Karnik et al. 1962; Vanek et al. 1962):

$$
M s=\log (A / T)+1.66 \log \Delta+3.30,
$$

where $A$ is the peak amplitude of the surface waves in micrometers, $T$ is the period in seconds, and $\Delta$ is the epicentral distance in degrees. First, the surface wave magnitude for the MVLP was calculated to be $M s=5.07 \pm 0.22$. Cesca et al. (2020) estimated a similar value of $M s=5.1$. Second, we calculated the surface wave magnitudes for the 24 regular earthquakes with body wave magnitudes 


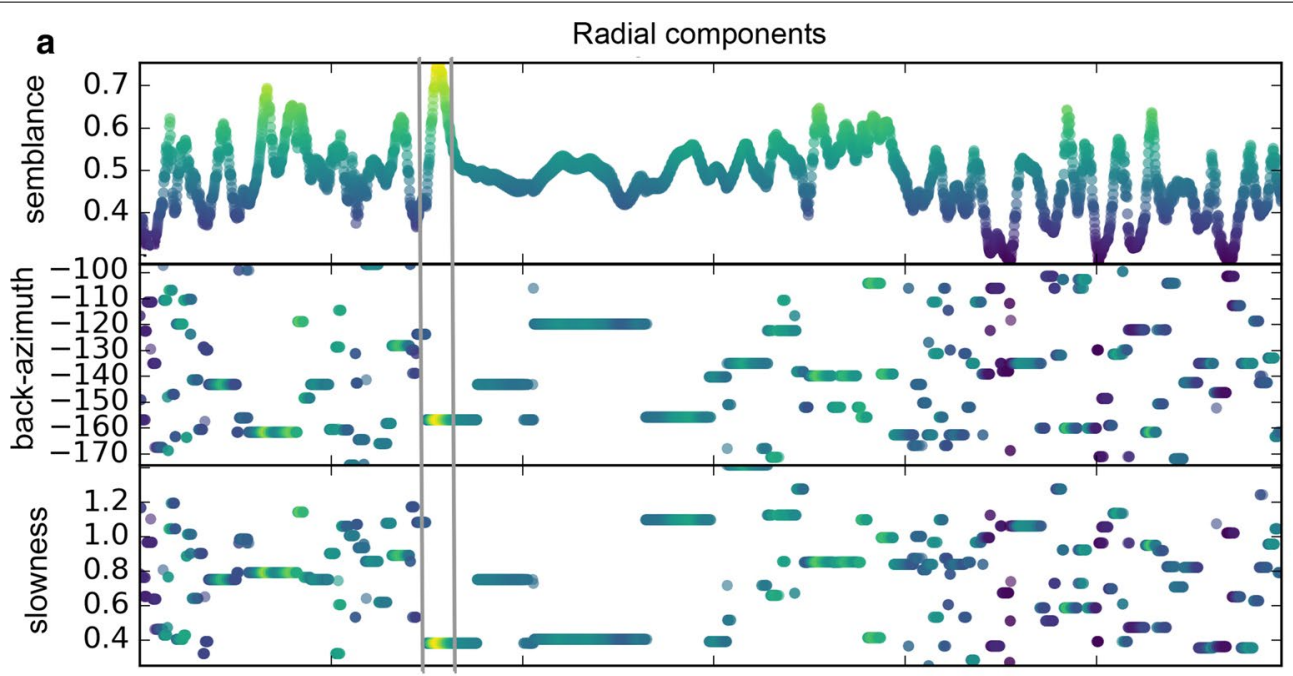

b

Transverse components

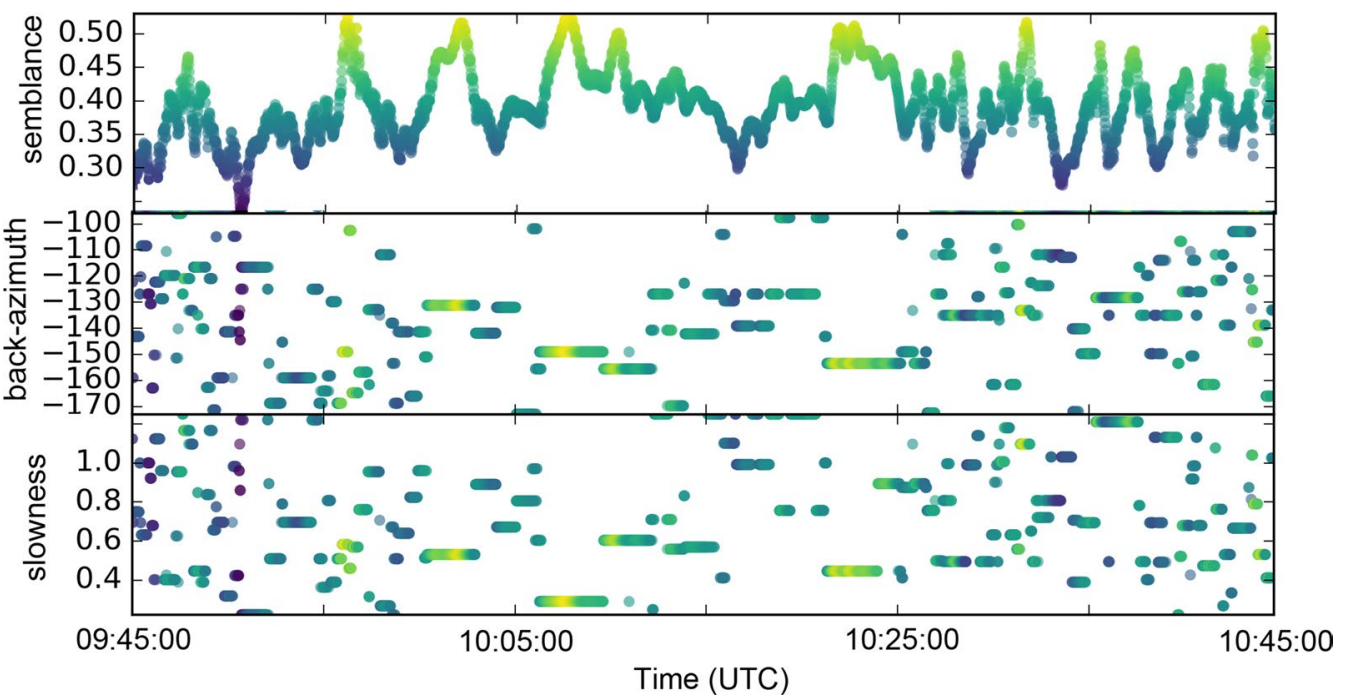

Fig. 7 Semblance values, back-azimuth in degrees, and apparent slowness in s/km for radial components (a) and transverse components (b) of MVLP. Data from nine array stations (red triangles in Fig. 1) were used. The pair of vertical gray lines in a indicates the solution with the maximum semblance value of $0.75 \%$

( $m b$ presented by USGS) $>4.5$ occurring from May 13 to June 1, 2018. The surface wave magnitudes for the selected events were calculated using averages of at least 10 amplitude readings. These $M s$ values and body wave magnitudes $(m b)$ are listed in the Table in the Appendix. It is important to note that the biggest earthquake is $m b=5.8$ and a lower limit of $m b=4.5$ was defined based on the signal strength and quality for reliable amplitude measurements. Then, we compared the relationship between $M s$ and $m b$, as shown in Fig. 9. Assuming that the best regression equation between $M s$ and $m b$ has the form $m b=a+b M s$, we obtained Eq. (3):

$$
m b=2.54( \pm 0.29)+0.56( \pm 0.07) M s, \text { std }=0.15, R^{2}=0.76
$$

Equation 3 shows that the average $M s$ in the range of $4.5-5.8$ is lower by $0.5-0$ than $m b$ on average. Scordilis (2006) studied empirical global relations for magnitude scale conversions and found nearly the same result for $M s<6.2$. We defined the converted body wave magnitude, $m b$ (conv), using the following Eq. (4):

$$
m b(\text { conv }) \equiv 2.54+0.56 M s .
$$

The obtained $m b$ (conv) values are listed in Table 1 for the three largest earthquakes and the MVLP. The 


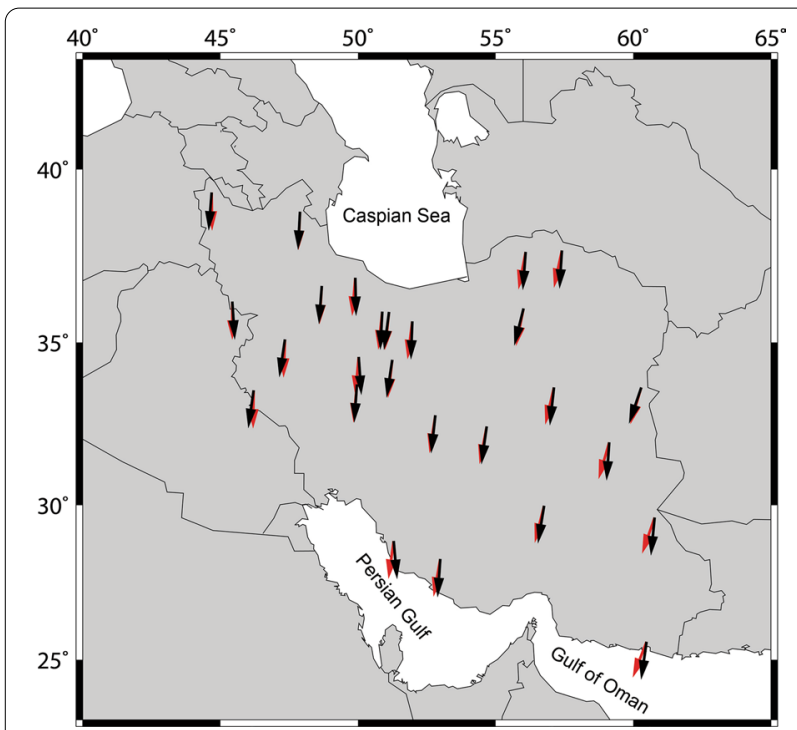

Fig. 8 Estimated back-azimuth (black arrow) at each station using both Rayleigh and Love waves of MVLP (see text). Red arrows show the direction to the epicenter of MVLP (Lemoine et al. 2020) from each station

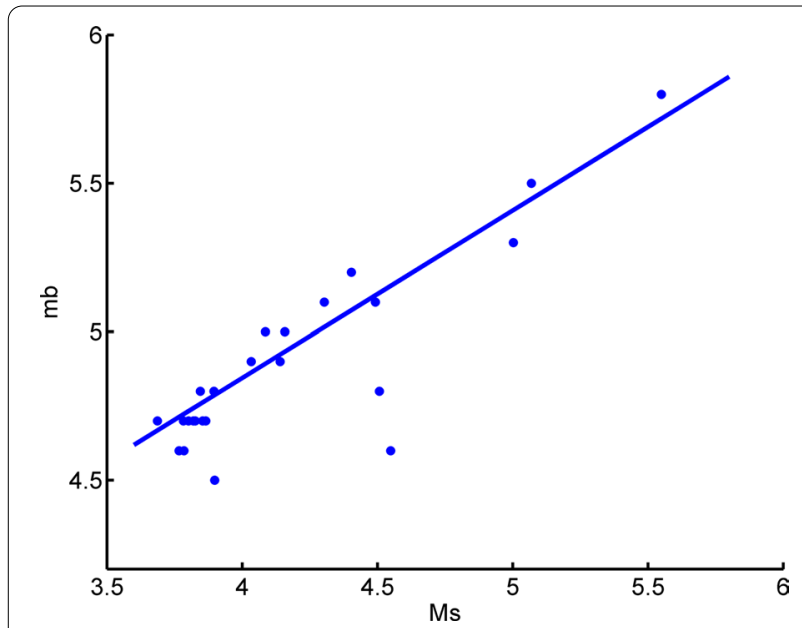

Fig. 9 Relation between the calculated surface wave magnitude and the body wave magnitude estimated by USGS

hypocenters of the three regular earthquakes were obtained from USGS, while the location of the MVLP was assumed from the source location that best fit the ground deformation after the early July 2018 event reviewed by Lemoine et al. (2020).

\section{Trigger earthquake just before MVLP}

Lemoine et al. (2020) stated that no strong earthquakes preceded the MVLP event, but some earthquakes are embedded in its seismic record, especially at the beginning of the monochromatic MVLP signal. Here, we want to take a closer look at the beginning of the signal to investigate the possibility of an earthquake occurring before and triggering the MVLP. Figure 10 shows the waveform and time variation of the dominant period at the ASAO station for the vertical component of the MVLP. It is clear from the figure that immediately before the arrival of the long-lasting monochromatic signal of the MVLP, the surface waves (Rayleigh waves) are dispersed. The period decreases from 17.5 to $16 \mathrm{~s}$ during the time period from 09:56:56 to 09:58:38 UTC, for about $100 \mathrm{~s}$, as shown in Fig. 10b. This could be the result of the occurrence of a regular earthquake just before the MVLP event. We call this event the "just before the monochromatic event" (JBE) in this paper. Compared with the arrival time of the equivalent dominant periods of the regular earthquakes (listed in Table 1) that occurred in the vicinity of the MVLP, the origin time of the JBE was estimated to be 09:27:56 UTC $\pm 13 \mathrm{~s}$. The surface wave magnitude of $M s=4.3 \pm 0.11$ was calculated for JBE. Cesca et al. (2019) detected a volcano-tectonic earthquake at 09:27:59.575 on November 11, 2018, at a latitude of $12.8058^{\circ} \mathrm{S}$ and a longitude of $45.4736^{\circ}$ E. They determined its magnitude based on a regional moment tensor inversion following the record of $M w$ 3.8 at a single strong-motion station on Mayotte Island. This earthquake must be the JBE. Now, the question is, how long before the MVLP did it occur? An answer can be obtained by comparing the frequency of these two events. Figure 10b shows that the dominant period curve for the JBE is bent at around the 16-s period at 09:58:38 UTC (red arrow). This may suggest that the surface wave of the JBE lasted until at least 09:58:38 UTC. For a more accurate determination, we applied a notch (a band-stop with narrow stopband) filter to separate the two merged events. In the spectrum of the MVLP, the largest peak is at $15.6 \mathrm{~s}$. Therefore, we filtered out the 15.6-s signal from the waveform using the notch filter to remove the main component of the MVLP signal. The results are shown in Fig. 10c. This figure shows that the filter removed the main content of the waveform corresponding to the long-duration monochromatic signal of the MVLP after 09:59:09 UTC (black arrow). This suggests that the MVLP surface wave arrived at 09:59:09 UTC at the latest. When we assume that the difference in surface wave velocities between the periods of 15.6 and $16 \mathrm{~s}$ are nearly the same, the time difference between 09:58:38 UTC and 09:59:09 UTC may suggest that the JBE occurred less than $31 \mathrm{~s}$ before the start of the MVLP. Because the interpretation of the MVLP triggering mechanism may differ depending on the accuracy of the delay time between the JBE and MVLP, we examined the record of the ABPO broadband station in Madagascar (Fig. 1). Figure 11 shows the recorded waveforms filtered at different frequency 
Table 1 Hypocenter location and magnitudes [mb, Ms, and mb(conv)] for the three largest earthquakes occurring during May 2018 and the MVLP and JBE occurring on November 11, 2018

\begin{tabular}{|c|c|c|c|c|c|c|c|c|}
\hline \multirow[t]{3}{*}{ No* or name } & \multirow{3}{*}{$\begin{array}{l}\text { Date } \\
\text { Year-Month-Day }\end{array}$} & \multicolumn{4}{|l|}{ Hypocenter } & \multicolumn{3}{|c|}{ Magnitude } \\
\hline & & \multirow[t]{2}{*}{ Origin Time (UTC) } & \multicolumn{3}{|c|}{ Location } & \multirow[t]{2}{*}{$\mathrm{mb}$} & \multirow[t]{2}{*}{ Ms } & \multirow{2}{*}{$\begin{array}{l}\text { mb } \\
\text { (conv) }\end{array}$} \\
\hline & & & Lat. $\left({ }^{\circ} \mathrm{S}\right)$ & Lon. $\left({ }^{\circ} \mathrm{E}\right)$ & Depth (km) & & & \\
\hline 19 & 2018-05-15 & 15:48:09 & 12.776 & 45.581 & 17 & 5.8 & 5.6 & 5.7 \\
\hline 15 & 2018-05-20 & 08:01:27 & 12.798 & 45.668 & 10 & 5.3 & 5.0 & 5.3 \\
\hline 14 & 2018-05-21 & $00: 47: 14$ & 12.850 & 45.654 & 10 & 5.5 & 5.1 & 5.4 \\
\hline MVLP & 2018-11-11 & $\sim 09: 28$ & 12.777 & 45.590 & 28 & - & 5.1 & 5.4 \\
\hline JBE & 2018-11-11 & $\sim 09: 28$ & $12.777 ?$ & $45.590 ?$ & $28 ?$ & - & 4.3 & 4.9 \\
\hline
\end{tabular}

${ }^{*}$ This is the number of the regular earthquakes listed in Appendix

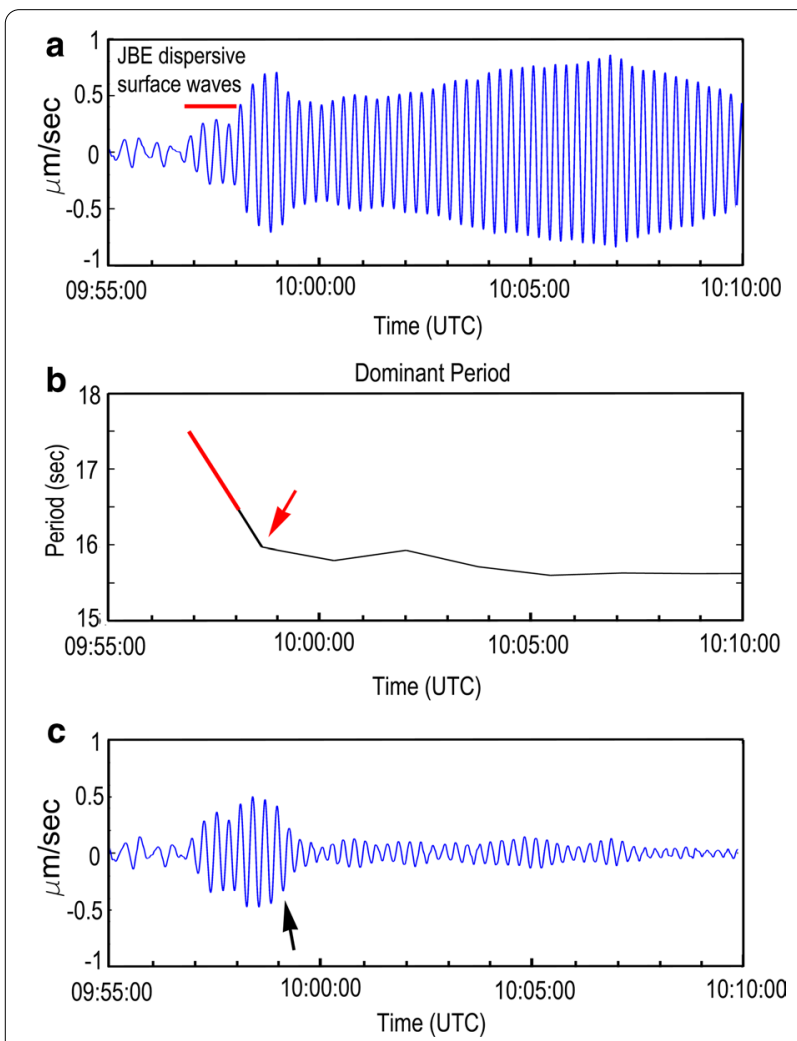

Fig. 10 a Enlargement of the right side of the top plot of Fig. 3. JBE and MVLP waveforms can be seen. $\mathbf{b}$ Dominant periods of the waveforms in $\mathbf{a}$. The dispersion of the surface waves is clear, and in the range of periods from 17.5 to $16.5 \mathrm{~s}$ is visible in the waveform (marked by red line). The red arrow indicates 09:58:38 UTC. c Notch filter output of the waveform with the notch in the period of $15.6 \mathrm{~s}$ and a bandwidth of $1 \mathrm{~s}$. The black arrow indicates 09:59:09 UTC

bands. The presence of several volcano-tectonic earthquakes accompanying the MVLP is seen in Fig. 11a. The first is the JBE, which makes the arrival of the $\mathrm{P}$ and $\mathrm{S}$ waves more clearly visible when enlarged (Fig. 11b). The first arrival time for the JBE Rayleigh wave and the time
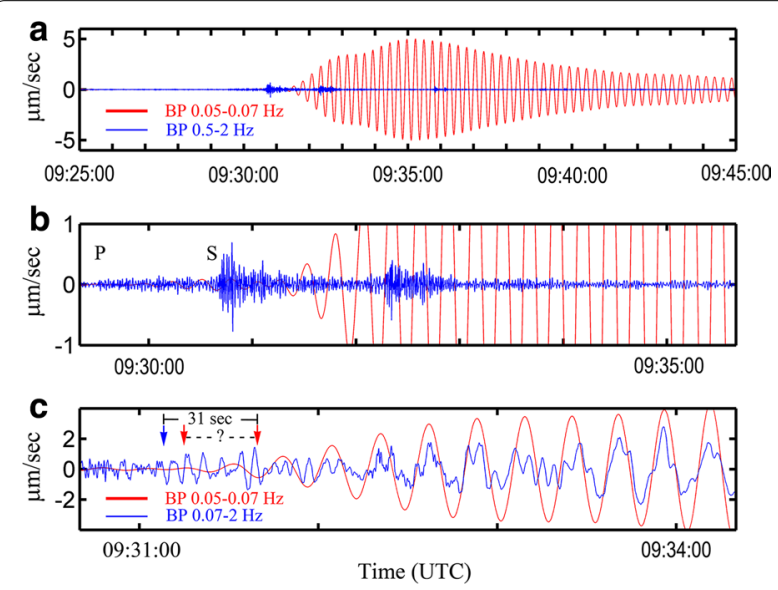

Fig. 11 Filtered seismic records of the vertical component at the ABPO broadband station in Madagascar. a Multiple volcano-tectonic signals accompanying the waveform of MVLP. $\mathbf{b}$ Part of panel $\mathbf{a}$ enlarged to show arrivals of the P and S phases of JBE. $\mathbf{c}$ Part of panel b enlarged to compare the arrival of the MVLP surface wave and JBE Rayleigh wave. The blue line shows the record through a $0.07-$ to $2-\mathrm{Hz}$ filter. The blue arrow indicates that the JBE Rayleigh wave arrived at 09:31:08. The MVLP surface wave seems to arrive between 09:31:15 (first red arrow) and 09:31:39 (second red arrow)

interval for the MVLP arrival are marked in Fig. 11c. Regardless of the difference in group velocity due to the Rayleigh wave period, the MVLP surface wave appears to start $\sim 7 \mathrm{~s}$ after the JBE arrival, as shown in Fig. 11c. However, it is difficult to mark the MVLP onset accurately.

Globally observed long-lasting monochromatic surface waves with dominant periods of about 230 and $270 \mathrm{~s}$, generated by the 1991 Mt. Pinatubo eruption (Philippines), were reported by Watada and Kanamori (2010). They demonstrated that the mechanism of these harmonic ground motions can be explained by the resonant oscillation between the atmosphere acoustic waves and the Rayleigh waves in the solid Earth. Both MVLP and Pinatubo Rayleigh waves are monochromatic but their 
wave periods are quite different. The mechanism of what controls the $16 \mathrm{~s}$ wave period of MVLP is not clear yet. We hope the existence of JBE before MVLP confirmed by this study serves as a stepping stone to unveil the generating mechanism of MVLP.

\section{Conclusions}

We studied the Mayotte MVLP, which occurred on November 11, 2018, using the records of the Iranian National Broadband Seismic Network. Long-lasting, monotonic long-period surface waves are visible and dominate the waveforms. The frequency of the monochromatic signals is $0.064 \mathrm{~Hz}$. The radiation pattern of the surface waves supports a vertical CLVD source mechanism. Apparent phase velocities of 3.31 and $2.97 \mathrm{~km} / \mathrm{s}$, respectively, for the Love and Rayleigh waves of the event were obtained from the results of our array analysis. The surface wave magnitude of the MVLP was estimated to be $M s=5.1$. Evidence of dispersion of the surface waves just before the arrival of the monochromatic event suggests that the MVLP was triggered by a regular earthquake with a magnitude of $M s=4.3$, which occurred around 09:28 UTC.

\section{Appendix}

List of the regular earthquakes whose surface wave magnitudes $(M s)$ were estimated using Eq. (2). Data except $M s$ and $m b$ (conv) were presented by USGS.

\begin{tabular}{|c|c|c|c|c|c|c|c|c|}
\hline \multirow[t]{3}{*}{ No } & \multirow{3}{*}{$\begin{array}{l}\text { Date } \\
\\
\text { Year- } \\
\text { Month- } \\
\text { Day }\end{array}$} & \multicolumn{4}{|c|}{ Hypocenter } & \multicolumn{3}{|c|}{ Magnitude } \\
\hline & & \multirow{2}{*}{$\begin{array}{l}\text { Origin } \\
\text { time } \\
\text { (UTC) }\end{array}$} & \multicolumn{3}{|l|}{ Location } & \multirow[t]{2}{*}{$\mathrm{mb}$} & \multirow[t]{2}{*}{ Ms } & \multirow{2}{*}{$\begin{array}{l}\mathrm{mb} \\
\text { (conv) }\end{array}$} \\
\hline & & & $\begin{array}{l}\text { Lat. } \\
\text { (degree) }\end{array}$ & $\begin{array}{l}\text { Lon. } \\
\text { (degree) }\end{array}$ & $\begin{array}{l}\text { Depth } \\
(\mathrm{km})\end{array}$ & & & \\
\hline 1 & $\begin{array}{l}\text { 2018-06- } \\
01\end{array}$ & $08: 28: 20$ & -12.7835 & 45.7277 & 10 & 4.6 & 3.8 & 4.7 \\
\hline 2 & $\begin{array}{l}\text { 2018-06- } \\
01\end{array}$ & 05:44:11 & -12.787 & 45.6429 & 10 & 4.8 & 4.5 & 5.1 \\
\hline 3 & $\begin{array}{l}\text { 2018-05- } \\
\quad 31\end{array}$ & 08:43:51 & -12.8613 & 45.6788 & 10 & 4.7 & 3.8 & 4.7 \\
\hline 4 & $\begin{array}{l}\text { 2018-05- } \\
31\end{array}$ & $01: 10: 14$ & -12.9066 & 45.6867 & 10 & 4.8 & 3.6 & 4.6 \\
\hline 5 & $\begin{array}{c}2018- \\
-05- \\
30\end{array}$ & $19: 11: 21$ & -13.126 & 45.2157 & 10 & 4.7 & 3.8 & 4.7 \\
\hline 6 & $\begin{array}{l}2018-05- \\
28\end{array}$ & 22:12:35 & -12.7924 & 45.6448 & 10 & 4.7 & 3.7 & 4.6 \\
\hline 7 & $\begin{array}{l}2018-05- \\
28\end{array}$ & $17: 09: 27$ & -12.8679 & 45.5989 & 10 & 4.7 & 3.8 & 4.7 \\
\hline 8 & $\begin{array}{l}2018-05- \\
28\end{array}$ & 13:55:16 & -12.8749 & 45.7628 & 10 & 4.9 & 4.0 & 4.8 \\
\hline 9 & $\begin{array}{l}2018-05- \\
27\end{array}$ & $14: 23: 27$ & -12.8871 & 45.6632 & 13.16 & 4.7 & 3.9 & 4.7 \\
\hline 10 & $\begin{array}{l}2018-05- \\
26\end{array}$ & $00: 32: 40$ & -12.8048 & 45.6915 & 10 & 5.0 & 4.1 & 4.8 \\
\hline
\end{tabular}

\begin{tabular}{|c|c|c|c|c|c|c|c|c|}
\hline \multirow[t]{3}{*}{ No } & \multirow{3}{*}{$\begin{array}{l}\text { Date } \\
\\
\text { Year- } \\
\text { Month- } \\
\text { Day }\end{array}$} & \multicolumn{4}{|c|}{ Hypocenter } & \multicolumn{3}{|c|}{ Magnitude } \\
\hline & & \multirow{2}{*}{$\begin{array}{l}\text { Origin } \\
\text { time } \\
\text { (UTC) }\end{array}$} & \multicolumn{3}{|l|}{ Location } & \multirow[t]{2}{*}{$\mathrm{mb}$} & \multirow[t]{2}{*}{ Ms } & \multirow{2}{*}{$\begin{array}{l}\mathrm{mb} \\
\text { (conv) }\end{array}$} \\
\hline & & & $\begin{array}{l}\text { Lat. } \\
\text { (degree) }\end{array}$ & $\begin{array}{l}\text { Lon. } \\
\text { (degree) }\end{array}$ & $\begin{array}{l}\text { Depth } \\
(\mathrm{km})\end{array}$ & & & \\
\hline 11 & $\begin{array}{l}\text { 2018-05- } \\
25\end{array}$ & 09:32:46 & -12.8542 & 45.6124 & 10 & 5.2 & 4.4 & 5 \\
\hline 12 & $\begin{array}{l}2018-05- \\
25\end{array}$ & 06:36:04 & -12.8192 & 45.5905 & 10 & 5 & 4.2 & 4.9 \\
\hline 13 & $\begin{array}{l}2018-05- \\
22\end{array}$ & $12: 37: 08$ & -12.852 & 45.6146 & 10 & 5.1 & 4.3 & 4.9 \\
\hline 14 & $\begin{array}{l}\text { 2018-05- } \\
21\end{array}$ & $00: 47: 14$ & -12.8495 & 45.6536 & 10 & 5.5 & 5.1 & 5.4 \\
\hline 15 & $\begin{array}{l}2018-05- \\
20\end{array}$ & $08: 01: 27$ & -12.7977 & 45.6684 & 10 & 5.3 & 5.0 & 5.3 \\
\hline 16 & $\begin{array}{l}\text { 2018-05- } \\
19\end{array}$ & 21:00:01 & -12.8377 & 45.6371 & 10 & 4.9 & 4.1 & 4.8 \\
\hline 17 & $\begin{array}{l}2018-05- \\
19\end{array}$ & 05:17:01 & -12.9013 & 45.7547 & 10 & 4.7 & 3.9 & 4.7 \\
\hline 18 & $\begin{array}{l}\text { 2018-05- } \\
15\end{array}$ & $20: 25: 17$ & -12.8801 & 45.5793 & 10 & 4.7 & 3.8 & 4.7 \\
\hline 19 & $\begin{array}{l}\text { 2018-05- } \\
15\end{array}$ & 15:48:09 & -12.7763 & 45.581 & 17 & 5.8 & 5.6 & 5.7 \\
\hline 20 & $\begin{array}{l}\text { 2018-05- } \\
15\end{array}$ & $11: 26: 50$ & -12.8377 & 45.6379 & 10 & 4.8 & 3.9 & 4.7 \\
\hline 21 & $\begin{array}{l}\text { 2018-05- } \\
15\end{array}$ & 08:58:18 & -12.8584 & 45.6601 & 15 & 4.6 & 4.6 & 5.1 \\
\hline 22 & $\begin{array}{l}\text { 2018-05- } \\
14\end{array}$ & $14: 41: 42$ & -12.8307 & 45.6127 & 10 & 5.1 & 4.5 & 5.1 \\
\hline 23 & $\begin{array}{l}\text { 2018-05- } \\
14\end{array}$ & 04:12:02 & -12.8283 & 45.6282 & 10 & 4.5 & 3.9 & 4.7 \\
\hline 24 & $\begin{array}{l}2018-05- \\
13\end{array}$ & 04:28:02 & -12.9418 & 45.408 & 10 & 4.6 & 3.8 & 4.7 \\
\hline
\end{tabular}

\section{Abbreviations}

CLVD: Compensated linear vector dipole; mb(conv): Converted body wave magnitude; f-k: Frequency-wavenumber; IIEES: International Institute of Earthquake Engineering and Seismology; JBE: Just before the monochromatic event; MT: Moment tensor; MVLP: Monotonic very-long-period; PSD: Power spectral density.

\section{Acknowledgements}

The authors are very thankful to O. Murakami for valuable discussions and guidance, to G. Javan Doloei and A. Ashari for sending us the seismic waveform data from the IIEES network, and also to A. Lemoine for providing us with the Bertil et al. (2019) catalog for the Mayotte region seismicity. We are also grateful to the two anonymous reviewers for their constructive comments and detailed suggestions. The seismic data of the ABPO station used in this study were obtained from the IRIS/IDA seismic network II (http://dx.doi.org/ doi:10.7914/SN/II). Some figures were made using the Generic Mapping Tools (Wessel and Smith 1998) software package.

\section{Authors' contributions}

HS performed the data analysis, the evaluation of the results, and drafted the manuscript. SS contributed to the interpretation of the results and was involved in drafting the manuscript for intellectual content. Both authors read and approved the final manuscript.

Funding

No funding was obtained for this study or for preparation of this paper.

Availability of data and materials

The waveform data are available by request to the IIEES. 


\section{Declarations}

Ethics approval and consent to participate

Not applicable.

\section{Consent for publication}

Not applicable.

\section{Competing interests}

The authors declare that they have no competing interests.

\section{Author details}

${ }^{1}$ Department of Geology, Faculty of Science, Ferdowsi University of Mashhad Mashhad, Iran. ${ }^{2}$ Tono Research Institute of Earthquake Science, Association for the Development of Earthquake Prediction, Mizunami, Japan.

Received: 28 November 2020 Accepted: 25 March 2021 Published online: 21 April 2021

\section{References}

Bertil D, Roullé A, Lemoine A, Colombain A, Hoste-Colomer R, Gracianne C, Meza- Fajardo K, Maisonhaute E, Dectot G (2019) MAYEQSwarm2019: BRGM earthquake catalogue for the Earthquake Swarm located East of Mayotte, 2018 May 10th - 2019 May 15th. Available at DATA BRGM. https://doi.org/10.18144/rmg1-ts50. Accessed 18 Nov 2020

Beyreuther M, Barsch R, Krischer L, Megies T, Behr Y, Wassermann J (2010) ObsPy: a python toolbox for seismology. Seismol Res Lett 81:530-533

Bullen KE, Bolt BA (1985) Introduction to the theory of seismology. Cambridge University, Cambridge

Cesca S, Heimann S, Letort J, Razafindrakoto HNT, Dahm T, Cotton F (2019) Seismic catalogues of the 2018-2019 volcano-seismic crisis offshore Mayotte, Comoro Islands. V. 1.0 (October 2019). Available at GFZ Data Services. https://doi.org/10.5880/GFZ.2.1.2019.004. Accessed 18 Nov 2020

Cesca S, Letort J, Razafindrakoto HNT, Heimann S, Rivalta E, Isken MP, Nikkhoo M, Passarelli L, Petersen GM, Cotton F, Dahm T (2020) Drainage of a deep magma reservoir near Mayotte inferred from seismicity and deformation. Nat Geosci 13(1):87-93. https://doi.org/10.1038/s41561-019-0505-5

Havskov J, Ottemöller L (2010) Routine data processing in earthquake seismology. Springer, Berlin

IIEES (2020) International Institute for Earthquake Engineering and Seismology (IIEES). http://www.iiees.ac.ir. Accessed 18 Nov 2020
Karnik V, Kondorskaya NV, Riznichenko YU, Savarensky EF, Soloviev S, Shebalin NV, Vanek J, Zatopek A (1962) Standardization of the earthquake magnitude scale. Studia Geophys Geodet 6:41-48

Lemoine A, Briole P, Bertil D, Roullé A, Foumelis M, Thinon I, Raucoules D, Michele M, Valty P, Colomer RH (2020) The 2018-2019 seismo-volcanic crisis east of Mayotte, Comoros Islands: seismicity and ground deformation markers of an exceptional submarine eruption. Geophys J Int 223(1):22-44. https://doi.org/10.1093/gji/ggaa273

Neidell NS, Taner MT (1971) Semblance and other coherency measures for multichannel data. Geophysics 36(3):482-497. https://doi.org/10.1190/1. 1440186

Rösler B, van der Lee S (2020) Using seismic source parameters to model frequency-dependent surface-wave radiation patterns. Seismol Res Lett 91:992-1002. https://doi.org/10.1785/0220190128

Scordilis EM (2006) Empirical global relations converting MS and mb to moment magnitude. J Seismol 10:225-236

Shuler A, Ekstrom G, Nettles M (2013a) Physical mechanisms for vertical-CLVD earthquakes at active volcanoes. J Geophys Res 118:1569-1586. https:// doi.org/10.1002/jgrb.50131

Shuler A, Ekstrom G, Nettles M (2013b) Global observation of vertical-CLVD earthquakes at active volcanoes. J Geophys Res 118:138-164. https://doi. org/10.1029/2012JB009721

Vanek J, Zapotek A, Karnik V, Kondorskaya NV, Riznichenko YV, Savarensky EF, Soloviev SL, Shebalin NV (1962) Standardization of magnitude scales. IzV Akad Nauk SSSR Ser Geofiz 2:153-158

Watada S, Kanamori H (2010) Acoustic resonant oscillations between the atmosphere and the solid earth during the $1991 \mathrm{Mt}$. Pinatubo eruption J Geophys Res 115:B12319. https://doi.org/10.1029/2010JB007747

Wei-Haas M (2018) Strange waves rippled around the world, and nobody knows why. Natl Geogr Nov 28

Wessel P, Smith WHF (1998) New improved version of Generic Mapping Tools released. EOS Trans Am Geophys Union 79:579-579

\section{Publisher's Note}

Springer Nature remains neutral with regard to jurisdictional claims in published maps and institutional affiliations.

\section{Submit your manuscript to a SpringerOpen ${ }^{\circ}$ journal and benefit from:}

- Convenient online submission

- Rigorous peer review

- Open access: articles freely available online

- High visibility within the field

- Retaining the copyright to your article

Submit your next manuscript at springeropen.com 